\title{
A Study on the Packaging Information of Antibiotics Available in Bangladesh
}

\author{
Md. Shah Amran ${ }^{1}$ and Md. Najmul Islam² \\ ${ }^{1}$ Department of Pharmaceutical Chemistry, Faculty of Pharmacy, Dhaka University, Dhaka-1000, Bangladesh. \\ ${ }^{2}$ Department of Pharmacy, South East University, Banani, Dhaka, Bangladesh
}

\begin{abstract}
The samples of primary and secondary packaging items of antibiotics manufactured in Bangladesh or imported by local distributing agencies, were collected and thoroughly examined from 2009 to 2010 on the basis of 32 parameters. These parameters are usually regarded important for the labeling of any drug, from the view point of standards set by national regulatory agencies, such as Directorate General of Drug Administration (DGDA) and Bangladesh Standards and Testing Institution (BSTI). The primary and secondary packaging items of a total of 10 pharmaceutical industries have been collected, sorted/arranged and meticulously studied, and packaging parameters were accumulated for analysis. It has been observed that many of the important packaging information were either completely missing or not properly described on the labels, inserts, inner carton, outer carton and container. This study was aimed at examining to what extent the packaging information is provided in the primary and secondary packaging items of antibiotics.
\end{abstract}

Key words: Packaging information, antibiotic, cartoon, insert, label.

\section{Introduction}

The concept of packaging comes from our very nature that save the substances from contamination by dust, fiber, and microorganism and also from environmental factors such as oxygen, moisture and temperature (Amran et al., 2007). Drugs are life saving chemical substances and they can not be dispensed as such. According to the original definition by S.A. Waksman, antibiotics are substances which are produced by microorganisms and which exhibit either an inhibitory or destructive effect on other microorganisms. To combat microorganisms such as viruses, bacteria, fungi, protozoa and other organized parasites, medical science today makes use of a large variety of antibiotics and chemotherapeutic agents (Reiner; 1982). Drugs are chemical substances and as a result, they are also very much prone to contamination by dust, fiber, and microorganism and also by environmental factors. So packaging is needed to preserve the integrity of the product and its selection depends on product's physical and chemical characteristics, its protective needs and its marketing requirements. Packaging therefore can be defined as an economical means of providing, presentation, protection, identification/information, containment, convenience and compliance for a product during storage, carriage, display and the product is being used or administered. This total time scale must be within the shelf life of the product. A package consists of (i) the container in which the product is placed, (ii) the closure which seals the container, (iii) the carton or outer, which gives primary and secondary protection against mechanical and other environmental hazards, and also serves for the display of written information, (iv) the box in which multiples of the product are packed. Packs are classifies into two classes, (i) the primary pack - consists of those packaging components which form the part of the pack directly containing the product. The main functions of the primary pack are to contain and to restrict any chemical, climatic and biological or occasionally mechanical hazards which may cause or lead to product deterioration, and (ii) the secondary pack- the packaging external to the primary pack is known as the primary and secondary packaging. It mainly provides the additional physical protection and patients' information (Corce et al., 1986; Dean, 1988; Rawlins, 1992; Giles and Pecina, 1985;

Correspondence to: Md. Shah Amran, Tel: +88-02-9661973 Extn: 8151, Fax: 88-02-8615583, Mobile: 88-01718617915, E-mail: amdshah_69@yahoo.com 
Khan, 1990; British Pharmacopoeia, 1988; Harburn, 1990; Gennaro, 1990).

Antibiotic medicines are those that satisfy the health care needs of the majority of the population to cure them from the microbial infection. They should be available at all times in adequate amounts and in the appropriate dosage forms, and at a price that individuals and the community can afford (Bangladesh National Formulary, 2001; WHO, 2005). World Health Organization (WHO) in its $36^{\text {th }}$ report on 'WHO expert committee on specifications for pharmaceutical preparations' (Annex 9 Guidelines on packaging for pharmaceutical products) proposes some parameters that must be printed on the primary and secondary packaging items (WHO, 2003). These are, for example, (a) the name of the product, (b) a list of the active ingredients showing the amount of each present and a statement of net contents, e.g. number of dosage units, mass or volume, (c) the batch number assigned by the manufacturer, (d) the expiry date in an uncoded form, (e) any special storage conditions or handling precautions that may be necessary, (f) the directions for use, and any warnings and precautions that may be necessary, (g) the name and address of the manufacturer or the company or person responsible for placing the product on the market. These are the generalized parameters but the detail information that should be printed on the primary and secondary packaging items must be specified by respective national legislation.

According to the Bangladesh Standards and Testing Institution (BSTI) standards, the packaging and labeling of a product should contain following information: (i) Name and Brand name (if any), (ii) Grade/Type/Size/voltage (if any), (iii) Weight/ Amount, (iv) Code/Batch No., (v) Ingredients of the product, (vi) Date of manufacture, (vii) Date of expiry, (viii) Name and address of original manufacturer (ix) Maximum retail price, (x) BDS No. with symbol of BDS, (xi) Name and address of manufacturer and importer (in case of imported goods), (xii) Name and address of Packing and marketing Company (Bangladesh Standard and Testing Institution, Physical Testing Wing).

Currently, a large number of antibiotic drugs of different manufacturers are available in the local market in various brand names. The patients as well as the physicians, largely rely on the information provided by the manufacturers on the labeling of these products. Does the labeling of these products bear all the necessary information and instructions? Are the information and instructions well presented and clearly displayed? In deed, this is a critical question for safe and effective use of drugs. Bangladesh is a developing country with poorly organized health care system. The drugs are rarely dispensed to the patients by qualified personnel or pharmacists. Therefore, importance of proper labeling is much more needed here and this is especially true for these products that are used at grass root level where qualified doctors, pharmacists, nurses are not sufficient / available for providing health care services. To the best of our knowledge no work has so far been performed in Bangladesh on instructions/packaging information provided by manufacturers for proper use of antibiotic drugs. In this background, the present work was performed to investigate whether or not the manufacturers provide all the necessary information and instructions on the labeling of antibiotic drugs available in the local market of Bangladesh.

\section{Materials and Methods}

The labeling samples used in this research work included labels, inner cartons and package inserts of the antibiotic drugs available in the local market (Dhaka metropolitan area). The samples were collected from different retail shops of Dhaka City from 2009 to 2010. We collected the labeling samples of 10 brands of drugs for this purpose.

The primary and secondary packaging items of a total of 10 different pharmaceutical companies were collected. A total of 30 primary and secondary packaging materials for all products have been accumulated. The samples were collected randomly so as to include all categories of national and multinational pharmaceutical industries. All the collected samples were coded properly and then packaging information of antibiotic drug products were accumulated for analysis. The following 32 parameters were selected for conducting the present study: (1) Trade name, (2) Generic name, (3) Name of the manufacturer, (4) Address of the manufacturer, (5) Composition, (6) Mechanism of action (Pharmacology), (7) Indication, (8) Contraindication, (9) Side effect, (10) Instruction for use, (11) Storage condition/Pharmaceutical precaution, (12) 
Warning, (13) Manufacturing date, (14) Expiry date, (15) Batch No./Lot No., (16) Manufacturing Licence No., (17) Product Licence No. (DAR no.), (18) Price, (19) Overdose, (20) Interaction, (21) Instruction for pediatric/geriatric/adult dose, (22) Use in pregnancy and lactation, (23) Sterility statement, (24) Dosage form (delivery system), (25) Preservative (in case of liquid/injection), (26) Time of rejection after opening, (27) Supply of the label or insert, (28) Dose to be administered, (29) How supplied (packaging quantity), (30) Volume of the product, (31) Legibility of the inserts and (32) Bilinguality.

These parameters were grouped as two classes, viz(i) General and Regulatory parameters and (ii) Clinical parameters. The general and regulatory parameters are: (1) Brand Name, (2) Generic Name, (3) Name of the Manufacturer, (4) Full Mailing Address of the Manufacturer, (5) Manufacturing Date, (6) Expiry Date, (7) Batch No./Lot No., (8) Manufacturing Licence, (9) Product Licence (DAR No.), (10) Maximum Retail Price, (11) Sterility Statement, (12) Supply of the label, (13) Packaging Quantity (net weight, amount) (14) volume of the product, (15) Legibility of the inserts, (16) Bilinguality and (17) Dosage form.

The clinical parameters are: (1) Composition or Ingredients, (2) Mechanism of action (Pharmacology), (3) Indication, (4) Contraindication, (5) Adverse/Side Effect, (6) Instruction for Use, (7) Warning, (8) Overdose, (9) Drug interaction, (10) Instruction for pediatric/Geriatric, (11) Use in pregnancy \& Lactation, (12) Dose to be administered, (13) Storage condition / Pharmaceutical precaution, (14) Time of the rejection after opening and (15) Preservative used.

\section{Results and Discussion}

We worked with 10 antibiotic drug products and presented the data of percent occurrences of packaging parameters of antibiotics drug products in Table 1a and 1b.

Table 1 show that many of the important packaging parameters did not occur for $100 \%$, that means they are missing. It was observed that many pharmaceutical companies in the supplied inserts wrote "More details are available on request" but almost all pharmaceutical companies did not give their full mailing address. How a patient, therefore, can request a specific pharmaceutical company? Most of the pharmaceutical companies, for example, wrote "The XYZ pharmaceutical Ltd., Bangladesh”. In our present study we found that not a single manufacturer (pharmaceutical company) wrote the full mailing address.

It is observed from the results that labeling of most drugs available in the local market had grave pitfalls. In case of antibiotics, not even a single product covered all the 32 parameters used to study the present work. Some important information, which is considered very important in the labeling of antibiotic products, was either missing or improperly described. Only a few manufacturer made in their labeling a statement about preservatives used (00\%), instruction for pediatric/geriatric /adult use (80\%), while these information are very important for safe and effective use of antibiotics (Carter, 1987; Clayton, 1972). Drug interaction (90\%), overdose (50\%), and storage condition/pharmaceutical precaution (80\%) were also not mentioned in the labeling of a great percentage of products. Full address of the manufacturer was not available in the labeling of any product, while it is indispensable for communication with the manufacturer if necessary.

The labeling of an antibiotic product must provide the physicians, healthcare providers or other users with all the information needed to assure the safe, effective and proper use of the therapeutic agent. It must contain a full and balanced presentation of the positive as well as the negative aspects of the drug product.

Clayton (1972) has drawn attention to the frequent need for special instructions to ensure that patients take medicines in a manner that produces maximum therapeutic effect. ${ }^{16-17}$ But the present study revealed that the primary and secondary packaging item of antibiotic drug products available in Bangladesh lacks much important information. Recently Marzban et al. (1998) conducted a research work on the labeling pattern of ophthalmic products available in Bangladesh on the basis of 21 parameters and inferred that many of the important packaging information were not available from the supplied labels, inserts and inner cartoons of the eye preparations available in the local market (Marzban et al. 1998). 
Table 1a. Percent occurrences of general and regulatory parameters for packaging of drug (Azithromycin).

\begin{tabular}{|c|c|c|c|c|c|c|c|c|c|c|c|c|}
\hline \multirow[t]{2}{*}{ Sl. } & \multirow[t]{2}{*}{ General and regulatory parameters } & \multicolumn{10}{|c|}{ Code name of the manufacturers } & \multirow{2}{*}{$\begin{array}{c}\% \\
\text { occurrence }\end{array}$} \\
\hline & & D1 & D2 & D3 & D4 & D5 & D6 & D7 & D8 & D9 & D10 & \\
\hline 1 & Trade name & + & + & + & + & + & + & + & + & + & + & 100 \\
\hline 2 & Generic name & + & + & + & + & + & + & + & + & + & + & 100 \\
\hline 3 & Name of the manufacturer & + & + & + & + & + & + & + & + & + & + & 100 \\
\hline 4 & Packaging quantity & + & + & + & + & + & + & + & + & + & + & 100 \\
\hline 5 & Full mailing address of manufacturer & - & - & - & - & - & - & - & - & - & - & 00 \\
\hline 6 & Manufacturing date & + & + & + & + & + & + & + & + & + & + & 100 \\
\hline 7 & Expiry date & + & + & + & + & + & + & + & + & + & + & 100 \\
\hline 8 & Batch No./Lot No. & + & + & + & + & + & + & + & + & + & + & 100 \\
\hline 9 & Manufacturing licence No. & + & + & + & + & + & + & + & + & + & + & 100 \\
\hline 10 & Price & + & + & + & + & + & + & + & + & + & + & 100 \\
\hline 11 & Volume of the product & + & + & + & + & + & + & + & + & + & + & 100 \\
\hline 12 & Ingredients & + & + & + & + & + & + & + & + & + & + & 100 \\
\hline 13 & Supply of the label & + & + & + & + & + & + & + & + & + & + & 100 \\
\hline 14 & Product licence (DAR No.) & + & + & + & + & + & + & + & + & + & + & 100 \\
\hline 15 & Sterility statement & + & + & + & + & + & + & + & + & + & + & 100 \\
\hline 16 & Legibility of the inserts & + & + & + & + & + & + & + & + & + & + & 100 \\
\hline 17 & Bilinguality & + & + & + & + & + & + & + & + & + & + & 100 \\
\hline
\end{tabular}

Table 1b. Percent occurrences of clinical parameters for packaging of drug (Azithromycin).

\begin{tabular}{|c|c|c|c|c|c|c|c|c|c|c|c|c|}
\hline \multirow[t]{2}{*}{$\mathrm{Sl}$} & \multirow[t]{2}{*}{ Clinical Parameters } & \multicolumn{10}{|c|}{ Code name of the manufacturers } & \multirow{2}{*}{$\begin{array}{c}\% \\
\text { occurrences }\end{array}$} \\
\hline & & D1 & D2 & D3 & D4 & D5 & D6 & D7 & D8 & D9 & D10 & \\
\hline 1 & Composition & + & + & + & + & + & + & + & + & + & + & 100 \\
\hline 2 & Mechanism of action (Pharmacology) & + & + & + & + & + & + & + & + & + & + & 100 \\
\hline 3 & Indication & + & + & + & + & + & + & + & + & + & + & 100 \\
\hline 4 & Contraindication & + & + & + & + & + & + & + & + & + & + & 100 \\
\hline 5 & Adverse/Side effect & + & + & + & + & + & + & + & + & + & + & 100 \\
\hline 6 & Instruction for use & + & + & + & + & + & + & + & + & + & + & 100 \\
\hline 7 & Warning & + & + & + & + & + & + & + & + & + & + & 100 \\
\hline 8 & Overdose & + & + & - & + & + & - & - & - & + & - & 50 \\
\hline 9 & Drug interaction & + & + & + & + & + & + & + & + & + & - & 90 \\
\hline 10 & Instruction for pediatric/Geriatric dose & + & - & + & + & + & + & + & - & + & + & 80 \\
\hline 11 & Use in pregnancy \& lactation & + & + & + & + & + & + & + & + & + & + & 100 \\
\hline 12 & Dose to be administered & + & + & + & + & + & + & + & + & + & + & 100 \\
\hline 13 & $\begin{array}{l}\text { Storage condition/Pharmaceutical } \\
\text { precaution }\end{array}$ & + & + & + & + & + & + & + & - & + & - & 80 \\
\hline 14 & Time of the rejection after opening & - & - & - & - & - & - & - & - & - & - & 00 \\
\hline 15 & Preservative used & - & - & - & - & - & - & - & - & - & - & 00 \\
\hline
\end{tabular}

$+=$ Presence of the parameter, - = Absence of the parameter.

Bangladesh has attained almost self-sufficiency in the pharmaceutical sector and in the current decade turned to be a medicine exporting country. There are about 235 pharmaceutical companies in the country engaged in producing quality allopathic medicines. In 1982 the annual market for pharmaceuticals was Tk. 243 crores but in 2010 it increased to 5500 crores. Now, about $95 \%$ of the medicines are manufactured in Bangladesh by national pharmaceutical industries. Moreover, Bangladesh is now a medicine exporting country. The manufacturers are now trying to export their pharmaceutical products to over 70 countries of the world. The multidisciplinary professional education of the pharmacists also ensured the quality of pharmaceutical products. Some leading pharmaceutical 
industries are certified by ISO 9000, GMP, TGA, FDA and European Union for their unique quality systems meaning that they are now able to do pharmaceutical business in the international arena. Some raw materials for medicine are also manufactured in our country. Along side that auxiliary or linkage industries (packaging \{paper, plastic, bottles, caps, tubes, and ampoules\}, printing etc.) are also developed. On the other hand, traditional medical care systems such as Unani, Ayurvedic and Homeopathy also play a major role in providing medical care to the peoples (Amran, 2003a,b,c; Amran, 2005). With such an excellent background, the lack of appropriate information on the primary and secondary packaging items is very unfortunate and unwanted. The exact and proper information on the primary and secondary packaging materials are also necessary to combat counterfeiting of medicinal products because counterfeiting may, sometimes, occur by mislabeling, mispackaging or change of the original package and deletion of expiry dates from the bottles or vials of pharmaceutical products. So, the manufacturers of pharmaceutical products should be more careful in designing the primary and secondary packaging items of antibiotic drug products. The Directorate General of Drugs Administration of Bangladesh also should formulate strict rules regarding labeling of pharmaceutical products including antibiotic drug products and also monitor strictly whether the manufacturers abide by the laws. Health professionals like nurses, health technologists (paramedics), pharmacists and doctors can play a pivotal role in counseling the patients on proper use of the antibiotic drug products and also by giving necessary suggestions to the manufacturers and the concerned drug authorities in developing proper packaging system for antibiotic drug products.

\section{Conclusion}

It has been found that many of the important packaging information both general and clinical were either completely missing or not properly described on the insets, labels, boxes or cartons of the antibiotic drugs either imported or locally manufactured and available in the local market of Bangladesh. Packaging information is equally important to doctors, pharmacists, nurses, patients and lay peoples.

\section{Acknowledgement}

This research project was funded by Bangladesh Medical Research Council (BMRC/HNPSP-RP/200809/776(1-86)).

\section{References}

Amran, M.S., Ahmed, M., Shaheen, S.M., Morshed S.N., Khandakar, M.J.A., Rahman, M.M., Rahman, M.M., and Hossain, M.A. 2007. A study on the packaging information of essential drug products used at Union and Thana health complex level in Bangladesh. Pak. J. Pharm. Sci. 20, 327332.

Amran, M.S. 2003 April 29-30. Trade-related aspects of intellectual property rights (TRIPS) and the pharmaceutical sector of Bangladesh. The Daily Bangladesh Observer.

Amran, M.S., 2003 June 10. The quality and price of Indian pharmaceutical products available in Bangladesh, The Weekly Jaijaidin, 19, 9-10.

Amran, M.S. 2003 November 07. Pharmacy as education and profession. As cover story in the Magazine of the daily Bangladesh Observer.

Amran, M.S. 2005 November 14, 15, 18, 26. How to combat spurious, substandard and counterfeit drugs? The daily Naya Diganta.

Bangladesh National Formulary (BDNF). 2001. Directorate of drug administration, Bangladesh Medical Association and Bangladesh Pharmaceutical Society, $1^{\text {st }}$ edition, 491-494.

Bangladesh Standard and Testing Institution, (Physical Testing Wing), 116/ka, Tejgoan I/A, Dhaka-1208.

British Pharmacopoeia, 1988. Volume I \& II, Appendix XIX, A211-18, UK.

Carter, S.J. (ed.). 1987. Cooper and Gunn's Dispensing for Pharmaceutical Students, $12^{\text {th }}$ ed., P 645, CBS Publishers \& Distributors, Delhi-110 032, India.

Clayton, R.A. 1972. An additional labeling system for prescriptions. Pharm. J. 209, 212.

Corce C.P., Fischer, A., and Thomas, R.H. 1986. Packaging materials science, In: The Theory and practice of industrial pharmacy, (Eds: Leon Lachman, L., Herbert A Lieberman, H.A., Kanig, J.L.), $3^{\text {rd }}$ edition, Lea and Febiger, USA, pp. 711-32.

Dean D.A. In: Pharmaceutics-the science of dosage form design, (Ed. M E Aulton), 1988. Packs for pharmaceutical products, ELBS, Churchill Livingstone, U.K. pp. 215-22.

Dean, D.A., 1988. In: Pharmaceutics-the science of dosage form design (Ed. M E Aulton). Packs of pharmaceutical products, ELBS, Churchill Livingstone, U. K. p. 712-24.

Gennaro, A.R. (ed.). 1990. In: Remington's Pharmaceutical Science, $18^{\text {th }}$ ed., P 1826, Mack Publishing Company, Easton, Persylvania 18042, USA. 
Giles, R.L., Pecina, R.W. 1985. In: Reminton's Pharmaceutical Sciences, (Ed. Alfonso R Gennaro), Plastic packaging materials, $17^{\text {th }}$ edition, Marck publishing company, USA, pp. 1473-77.

Harburn, K. 1990. Quality control of packaging materials in the pharmaceutical industry, Mercel Dekker Inc. New York, pp. 175.

Khan, M.S.N., 1990. Assurance of quality pharmaceuticals-total quality approach, Signet Press Ltd. Bangladesh, p. 61-75.

Marzban, M., Haider, S.S., and MDA Muhsin, M.D.A. 1998. Labeling pattern of ophthalmic products available in Bangladesh, Bangladesh. J. Life Sci. 10, 19-24.
Rawlins, E.A. (Ed.). 1992. Packaging, Bentley's textbook of pharmaceutics, $8^{\text {th }}$ edition, Bailliere Tindal, India, pp. 685709.

Reiner, R. 1982. Antibiotics, An Introduction, Roche edition, pp. 1-2.

WHO Model List of Essential Medicines, 2005. 14 $4^{\text {th }}$ edition, 124.

WHO Expert Committee on Specifications for Pharmaceutical Preparations, 2003. WHO technical report series $902,36^{\text {th }}$ report, Annex 9-Guidelines on packaging of Pharmaceutical Products. 